\title{
Correction
}

\section{Correction: Thürling et al., "Cerebellar Cortex and Cerebellar Nuclei Are Concomitantly Activated during Eyeblink Conditioning: A 7T fMRI Study in Humans"}

In the article, "Cerebellar Cortex and Cerebellar Nuclei Are Concomitantly Activated during Eyeblink Conditioning: A 7T fMRI Study in Humans" by Markus Thürling, Fabian Kahl, Stefan Maderwald, Roxana M. Stefanescu, Marc Schlamann, Henk-Jan Boele, Chris I. De Zeeuw, Jörn Diedrichsen, Mark E. Ladd, Sebastiaan K. E. Koekkoek, and Dagmar Timmann, which appeared on pages $1228-1239$ of the January 21, 2015 issue, the fourth author name is incorrect. Stefanescu RM (Roxana M. Stefanescu) should read Stefanescu MR (Maria R. Stefanescu). The corrected author list is as follows: Markus Thürling, Fabian Kahl, Stefan Maderwald, Maria R. Stefanescu, Marc Schlamann, Henk-Jan Boele, Chris I. De Zeeuw, Jörn Diedrichsen, Mark E. Ladd, Sebastiaan K. E. Koekkoek, and Dagmar Timmann. The fourth author name has been corrected in the online PDF version.

In addition, reanalysis of the original dataset revealed that incorrect data files had been selected to perform the analysis of conditioned response (CR) acquisition presented in Figure 5 and the corresponding Tables 2 and 5. Repeated-measures ANOVA had been applied to assess the effect of time across the five blocks of paired conditioned stimulus (CS)- unconditioned stimulus (US) trials (20 trials per block). The original, faulty data analysis suggested a significant change in fMRI signal across the acquisition phase with an initial increase and subsequent decrease (original Fig. $5 c, d$ ). Re-analysis of the dataset using the correct data files revealed no significant change of fMRI signal across acquisition blocks (i.e., no significant effect of time). Therefore, the results shown in the original Figure 5 and the corresponding Tables 2 and 5 are no longer valid. Re-analysis showed a main effect of acquisition versus rest in cerebellar

a

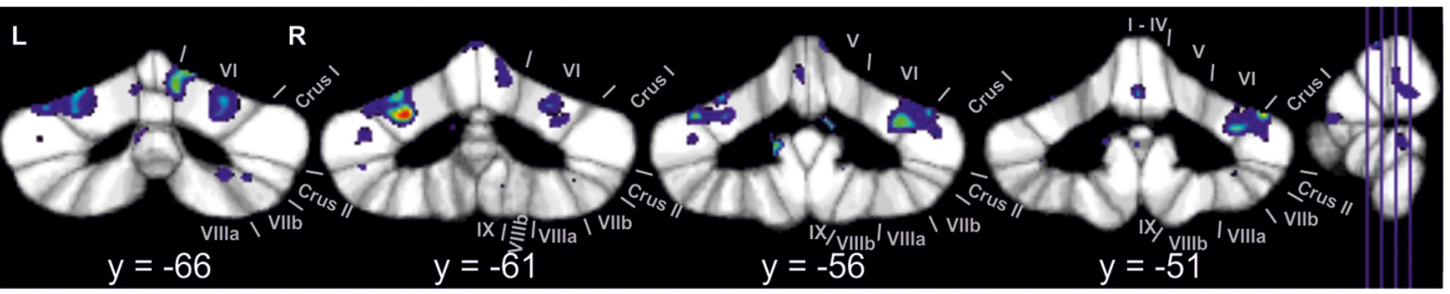

$t$ value $\mathbf{4 . 7} \quad 8.0$

$t$ value 3.6

b
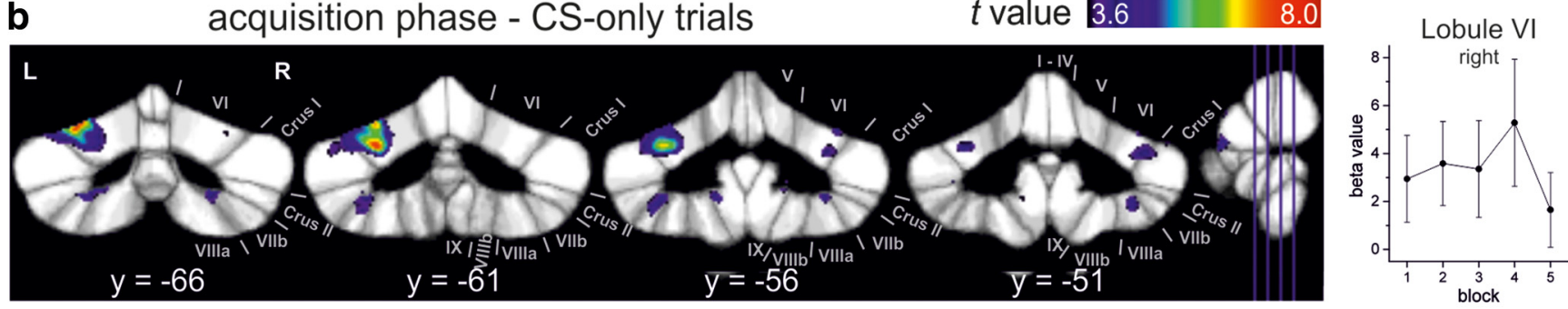

C

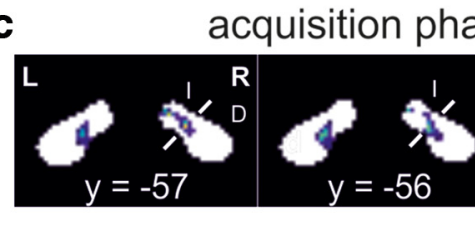

- paired CS-US trials

$t$ value 4.0
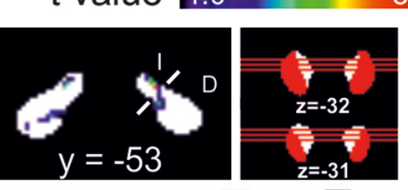

$\square$ Dentate $\square$ Interpose

\begin{tabular}{l}
$t$ value $2.5 \quad 4.0$ \\
\hline
\end{tabular}

d acquisition phase - CS-only trials
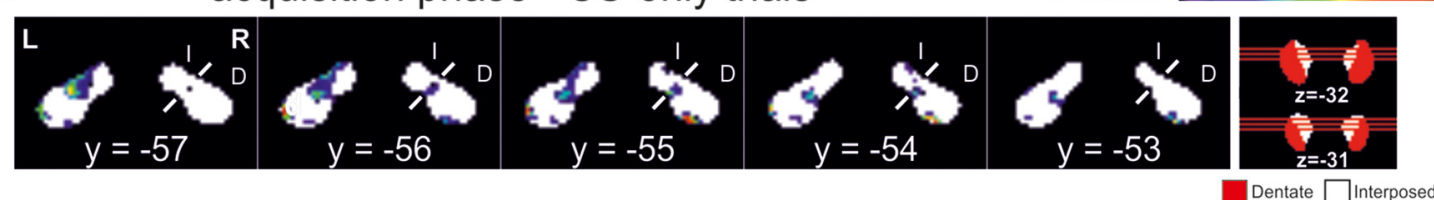
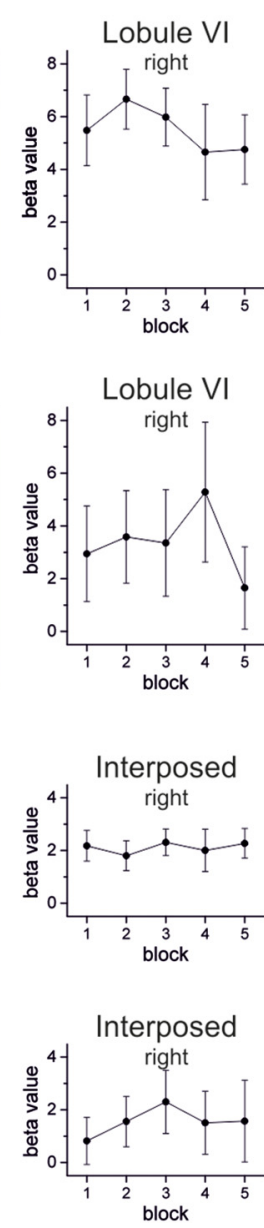

Figure 5. Cerebellar cortical $(\boldsymbol{a}, \boldsymbol{b})$ and nuclear $(\boldsymbol{c}, \boldsymbol{d})$ activations against rest in the acquisition phase and the corresponding mean $\beta$ values over blocks of 20 paired $C S-U S$ trials $(\boldsymbol{a}, \boldsymbol{c})$ and five $\mathrm{CS}$-only trials $(\boldsymbol{b}, \boldsymbol{d})$, respectively. The respective blocks were modeled individually in the first-level analysis. Activations were calculated using a one-sample $t$ test over first-level contrasts spanning all five acquisition blocks against rest. Results are thresholded at the level of $p<0.05$ (permutation corrected) for paired CS-US trials and for CS-only trials at a trend level (b: $p<0.001 ; \boldsymbol{d}: p<0.01$ uncorrected). $t$-maps are mapped onto coronal slices of the SUIT maximum probability template (Diedrichsen et al., 2009) and the newly developed dentate and interposed template. Mean $\beta$ values ( \pm SEM) are given for VOl of the right lobule VI and right interposed nuclei, respectively. ANOVA with repeated measures showed no significant block effects (all $p>0.6)$. L, Left; R, Right; $y, z$, SUIT coordinates (in millimeters); Roman numerals, cerebellar lobules; D, dentate; I, interposed. 
Table 2. Activity in cerebellar cortex during the acquisition phase

\begin{tabular}{|c|c|c|c|c|c|c|c|}
\hline \multirow{2}{*}{$\begin{array}{l}\text { Condition/cluster } \\
\text { Paired CS-US }\end{array}$} & \multirow[t]{2}{*}{ Side } & \multicolumn{3}{|c|}{$x, y, z(\mathrm{~mm})$} & \multirow[t]{2}{*}{ Location } & \multirow[t]{2}{*}{ Cluster voxel size $\left(\mathrm{mm}^{3}\right)$} & \multirow[t]{2}{*}{$t$} \\
\hline & & & & & & & \\
\hline 1. Main cluster & Bilateral & & & & $\begin{array}{l}\text { Left: V,VI, Crus I, Crus II, VIIb, VIIlla; vermis: VI, Crus I, Crus II, } \\
\text { VIIIb, VIIIla; right: V, VI, Crus I, Crus II, VIIb }\end{array}$ & 5123 & \\
\hline & Left & -11 & -77 & -30 & Crus I & 762 & 9.55 \\
\hline & Left & -7 & -76 & -15 & $\mathrm{VI}$ & 1202 & 6.64 \\
\hline & Right & 8 & -65 & -15 & V & 342 & 6.61 \\
\hline & Right & 8 & -76 & -31 & Crus II & 96 & 6.58 \\
\hline & Right & 10 & -74 & -18 & $\mathrm{VI}$ & 982 & 6.56 \\
\hline & Left & -12 & -72 & -23 & $\mathrm{VI}$ & 1202 & 5.81 \\
\hline & Vermis & 0 & -77 & -28 & Crus II & 116 & 5.70 \\
\hline & Left & -16 & -70 & -43 & VIllb & 200 & 5.67 \\
\hline & Left & -7 & -68 & -35 & VIllb & 200 & 5.67 \\
\hline 2. Extended cluster & Left & & & & VI, Crus I & 2209 & \\
\hline & Left & -25 & -61 & -26 & $\mathrm{VI}$ & 1920 & 7.87 \\
\hline & Left & -39 & -56 & -27 & Crus I & 289 & 6.28 \\
\hline & Left & -37 & -65 & -23 & VI & 1920 & 5.90 \\
\hline & Left & -25 & -75 & -20 & $\mathrm{VI}$ & 1920 & 5.08 \\
\hline 3. Extended cluster & Right & & & & VI, Crus I & 2754 & \\
\hline & Right & 44 & -51 & -26 & CrusI & 570 & 6.77 \\
\hline & Right & 32 & -56 & -29 & VI & 2184 & 6.48 \\
\hline & Right & 26 & -63 & -23 & VI & 2184 & 6.30 \\
\hline & Right & 38 & -56 & -23 & $\mathrm{VI}$ & 2184 & 5.36 \\
\hline 4. Extended cluster & Left & & & & I to IV & 70 & \\
\hline & Left & -6 & -40 & -18 & I to IV & 70 & 6.19 \\
\hline & Left & -9 & -41 & -28 & I to IV & 70 & 5.92 \\
\hline 5. Extended cluster & Bilateral & & & & I to IV left, I to IV right & 212 & \\
\hline & Left & 0 & -50 & -19 & I to IV & 151 & 5.94 \\
\hline & Left & -2 & -55 & -11 & I to IV & 151 & 5.42 \\
\hline 6. & Left & -11 & -54 & -41 & IX & 91 & 6.93 \\
\hline 7. & Bilateral & -1 & -62 & -1 & V left, V right & 62 & 5.87 \\
\hline 8. & Right & 27 & -69 & -46 & 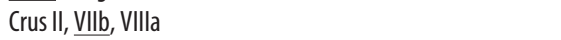 & 368 & 5.79 \\
\hline 9. & Right & 6 & -56 & -2 & I to IV, V & 31 & 5.65 \\
\hline 10. & Left & -39 & -61 & -33 & Crus I & 224 & 5.56 \\
\hline 11. & Vermis & 0 & -53 & -36 & $\underline{I X}, X$ & 53 & 5.44 \\
\hline 12. & Left & -40 & -59 & -45 & Crus I, Crus II & 35 & 5.25 \\
\hline 13. & Right & 33 & -48 & -51 & VIlb, VIIla & 67 & 5.15 \\
\hline CS-only & & & & & & & \\
\hline 1. Main cluster & Bilateral & & & & Left: VI, Crus I, Crus II, VIIb; vermis: VI, Crus I, Crus II; right: VI & 10778 & \\
\hline & Left & -27 & -64 & -19 & VI & 4648 & 7.30 \\
\hline & Left & -12 & -75 & -35 & Crus II & 2549 & 7.25 \\
\hline & Left & -27 & -61 & -27 & $\mathrm{Vl}$ & 4648 & 7.24 \\
\hline & Left & -20 & -77 & -41 & Crus II & 2549 & 6.56 \\
\hline & Left & -24 & -69 & -46 & VIllb & 1066 & 5.95 \\
\hline & Left & -19 & -71 & -26 & $\mathrm{Vl}$ & 4648 & 5.94 \\
\hline & Right & 8 & -75 & -17 & $\mathrm{VI}$ & 401 & 5.75 \\
\hline & Left & -11 & -74 & -21 & $\mathrm{VI}$ & 4648 & 5.38 \\
\hline 2. & Right/vermis & 7 & -77 & -34 & Vermis: VI, Crus II; right: VI,Crus I, Crus II & 618 & 6.54 \\
\hline 3. & Right & 33 & -50 & -50 & VIlb, VIlla & 213 & 4.76 \\
\hline 4. & Left & -10 & -55 & -47 & IX & 77 & 4.70 \\
\hline 5. & Right & 23 & -65 & -46 & VIIb, VIIIla & 160 & 4.37 \\
\hline 6. & Right & 38 & -52 & -30 & VI, Crus I & 354 & 4.24 \\
\hline 7. & Right & 35 & -56 & -21 & $\mathrm{VI}$ & 56 & 4.19 \\
\hline 8. & Right & 13 & -74 & -47 & VIllb & 40 & 4.06 \\
\hline
\end{tabular}

In first level analysis, five blocks of 20 paired CS-US events and 5 blocks of 5 CS-only events were modeled. Activations were calculated with a one-sample $t$ test over first-level contrasts spanning the five respective acquisition blocks. Results are thresholded at the level of $p<0.05$ (permutation corrected, $t=4.67$ ) for paired CS-US trials and at trend level ( $p<0.001$ uncorrected, $t=3.58$ ) for CS-only trials. Multiple local maxima within one cluster are reported with a minimum distance of $8 \mathrm{~mm}$. In single-peaked clusters spanning multiple lobules, peak location is underlined; in multipeaked clusters voxel size is presented for each lobule with a local peak, total voxel size is given in the first line.

cortical and nuclei areas known to contribute to CR acquisition [i.e., lobules VI with extension into Crus I and II and additional activation in lobules VIIb and VIII; interposed nuclei with additional activations in the dentate nuclei (see corrected Fig. 5 and Tables 2 and 5)]. The extension and the numbers of clusters were different compared with the original, faulty data analysis, but the main locations remained the same. Because the main effect of acquisition in paired CS-US trials does not allow differentiation between activations related to the $\mathrm{CR}$ and unconditioned response, additional analysis was performed considering interspersed CS-only trials (five blocks of CS-only trials, five trials per block). Again, no significant change of fMRI signal was observed across blocks. The main effect of acquisition versus rest showed a similar pattern of activation as in paired trials (see corrected Fig. $5 b, d$ and Tables 2 and 5). In addition, mean $\beta$ values were assessed in two volumes of interest (VOIs), the right lobule VI and the interposed nucleus. VOIs were 
Table 5. Activity in cerebellar nuclei during the acquisition phase

\begin{tabular}{|c|c|c|c|c|c|c|c|}
\hline \multirow{2}{*}{$\begin{array}{l}\text { Condition/cluster } \\
\text { Paired CS-US }\end{array}$} & \multirow[t]{2}{*}{ Side } & \multicolumn{3}{|c|}{$x, y, z(\mathrm{~mm})$} & \multirow[t]{2}{*}{ Location } & \multirow[t]{2}{*}{ Cluster voxel size $\left(\mathrm{mm}^{3}\right)$} & \multirow[t]{2}{*}{$t$} \\
\hline & & & & & & & \\
\hline \multirow[t]{5}{*}{ 1. Extended cluster } & Right & & & & Dentate and interposed & 194 & \\
\hline & Right & 11 & -59 & -32 & Dentate & 126 & 7.38 \\
\hline & Right & 12 & -53 & -30 & Interposed & 68 & 7.12 \\
\hline & Right & 13 & -53 & -34 & Dentate & 126 & 5.89 \\
\hline & Right & 8 & -56 & -29 & Interposed & 68 & 5.52 \\
\hline \multirow[t]{3}{*}{ 2. Extended cluster } & Left & & & & Dentate and interposed & 187 & \\
\hline & Left & -13 & -55 & -36 & Dentate & 160 & 5.87 \\
\hline & Left & -8 & -61 & -32 & Dentate & 160 & 5.53 \\
\hline 3. & Left & -10 & -54 & -30 & Interposed & 15 & 5.87 \\
\hline 4. & Left & -19 & -52 & -41 & Dentate & 9 & 4.55 \\
\hline \multicolumn{8}{|l|}{ CS-only } \\
\hline 1. & Left & -23 & -56 & -38 & Dentate & 34 & 4.26 \\
\hline 2. & Right & 17 & -54 & -41 & Dentate & 40 & 4.01 \\
\hline \multirow[t]{7}{*}{ 3. Extended cluster } & Left & & & & Dentate and interposed & 234 & \\
\hline & Left & -9 & -60 & -29 & Interposed & 74 & 3.93 \\
\hline & Left & -15 & -57 & -34 & Dentate & 160 & 3.48 \\
\hline & Left & -13 & -57 & -30 & Interposed & 74 & 3.20 \\
\hline & Left & -12 & -54 & -35 & Dentate & 160 & 3.11 \\
\hline & Left & -9 & -56 & -27 & Interposed & 74 & 3.03 \\
\hline & Left & -13 & -63 & -31 & Dentate & 160 & 2.71 \\
\hline \multirow[t]{3}{*}{ 4. Extended cluster } & Right & & & & Dentate and interposed & 62 & \\
\hline & Right & 10 & -60 & -35 & Interposed & 14 & 3.54 \\
\hline & Right & 15 & -61 & -37 & Dentate & 48 & 2.71 \\
\hline 5. & Right & 12 & -55 & -34 & Dentate and interposed & 21 & 3.26 \\
\hline 6. & Right & 23 & -61 & -36 & Dentate & 5 & 2.99 \\
\hline \multirow[t]{3}{*}{ 7. Extended cluster } & Left & & & & Dentate & 22 & \\
\hline & Left & -18 & -52 & -41 & Dentate & 22 & 2.96 \\
\hline & Left & -16 & -57 & -41 & Dentate & 22 & 2.89 \\
\hline 8. & Left & -19 & -52 & -34 & Dentate & 3 & 2.82 \\
\hline 9. & Right & 11 & -54 & -28 & Interposed & 5 & 2.59 \\
\hline 10. & Right & 13 & -54 & -31 & Interposed & 1 & 2.58 \\
\hline
\end{tabular}

In the first-level analysis, five blocks of 20 paired $(S-U S$ events and five blocks of five (S-only events were modeled. Activations were calculated with a one-sample $t$ test over first-level contrasts spanning the five respective acquisition blocks. Results are thresholded at the level of $p<0.05$ (permutation corrected, $t=4.03$ ) for paired (S-US trials and at trend level $(p<0.01$ uncorrected, $t=2.54)$ for CS-only trials. In single-peaked clusters spanning multiple nuclei, peak location is underlined; in multipeaked clusters, voxel size is presented for each cerebellar nucleus with a local peak; total voxel size is given in the first line.

chosen based on the animal eyeblink conditioning literature. Mean $\beta$ values were already high in the first acquisition block, both in the cerebellar cortex and the cerebellar nuclei (see mean $\beta$ values in corrected Fig. 5). fMRI signal showed no significant change across the five acquisition blocks in either the cerebellar cortex or in the cerebellar nuclei blocks (all $p>0.6$, repeated-measures ANOVA). This was the case considering the paired CS-US trials and, more importantly, considering the CS-only trials (see corrected Fig. $5 b, d$ ). We were able to replicate this finding in a follow-up study using the same experimental setup in a new group of participants (see Fig. 5 in Ernst et al., 2017). Similar to the present findings, the fMRI signal was found to increase in parallel within the cerebellar cortex and nuclei during CR acquisition. This increase was present already in the first acquisition block. Because neither the re-analysis nor the follow-up study revealed significant changes across time, results of main effects of acquisition phase based on one-sample $t$ tests are reported instead. The corrected Figure 5, Table 2, and Table 5 are provided above. Note that the main finding of the paper, concomitant activation of the cerebellar cortex and nuclei during initial acquisition of the classically conditioned eyeblink responses, remains the same.

\section{Details on the second-level fMRI analysis}

In the original data analysis, individual (first-level) evaluation was modeled as five blocks of 20 paired CS-US trials. Contrasts against rest were generated for each individual block. In the second-level analysis, the five paired trial blocks were compared using a withinsubject ANOVA and tested for significant changes across time, or the "block effect." The F contrast vector (SPM notation) is as follows: [1-1000;0 1-100;001-10;000 1-1]. An error occurred in the selection of the first-level contrasts for block 3, leading to a strong overestimation of these contrasts' $\beta$ values. A strong time effect was falsely detected. After replacement of block 3 with the correct block, within-subject ANOVA revealed no significant time (i.e., block) effects.

In the re-analysis, acquisition phase was modeled as five blocks of 20 paired CS-US trials and five blocks of five CS-only trials in first level. Again, a within-subject ANOVA as described above showed significant effects of time either in paired CS-US trials or in CS-only trials. We additionally generated first-level contrasts against rest considering all five blocks of paired CS-US trials and all five blocks of CS-only trials, respectively. In the second-level evaluation, one-sample $t$ tests were applied for these two sets of first-level contrasts. The results show the main effect of acquisition phase versus rest. 


\section{References}

Ernst TM, Thürling M, Müller S, Kahl F, Maderwald S, Schlamann M, Boele HJ, Koekkoek SKE, Diedrichsen J, De Zeeuw CI, Ladd ME, Timmann D (2017) Modulation of $7 \mathrm{~T}$ fMRI signal in the cerebellar cortex and nuclei during acquisition, extinction, and reacquisition of conditioned eyeblink responses. Hum Brain Mapp 38:3957-3974. CrossRef Medline

Diedrichsen J, Balsters JH, Flavell J, Cussans E, Ramnani N (2009) A probabilistic MR atlas of the human cerebellum. Neuroimage 46:39-46. CrossRef Medline

DOI:10.1523/JNEUROSCI.2133-17.2017 